\title{
Analysis of gender differences on pyriform aperture of human skulls using geometric morphometric method
}

\author{
A. Sarač-Hadžihalilović ${ }^{1}$, Z. Ajanović1 10 , I. Hasanbegović1, S. Šljuka², M. Rakanović-Todić3 \\ I. Aganović, I. Prazina ${ }^{5}$, S. Maleškić Kapo ${ }^{3}$, R. Hadžiselimović ${ }^{6}$ \\ 'Department of Anatomy, Faculty of Medicine, University of Sarajevo, Bosnia and Herzegovina \\ ${ }^{2}$ Department of Biology, Faculty of Science, University of Sarajevo, Bosnia and Herzegovina \\ ${ }^{3}$ Department of Pharmacology, Faculty of Medicine, University of Sarajevo, Bosnia and Herzegovina \\ ${ }^{4}$ Department of Immunology, Faculty of Medicine, University of Sarajevo, Bosnia and Herzegovina \\ ${ }^{5}$ University of Sarajevo, Bosnia and Herzegovina \\ ${ }^{6}$ Academician, Prof. Emeritus, Institute for Genetic Engineering and Biotechnology Sarajevo (INGEB), \\ University of Sarajevo, Bosnia and Herzegovina
}

[Received: 17 May 2021; Accepted: 12 June 2021; Early publication date: 24 August 2021]

Background: Piriform aperture is anterior opening of the nasal cavity formed by bones of the viscerocranium and knowledge about differences between genders is important for forensic scientists, anthropologists, orthopaedists, neurosurgeons and vascular surgeons. The aim of this study was to examine gender differences of piriform aperture on three-dimensional (3D) models of human skulls originating from Bosnian population using the geometric morphometric method.

Materials and methods: The study was conducted on 211 3D models of human skulls of known gender. 3D models were obtained by laser scanning. We analysed the gender differences of piriform aperture using geometric morphometrics method. On 3D models we marked four landmarks on piriform aperture in the Landmark Editor programme, after which we analysed its gender differences in MorphoJ programme.

Results: The first principal component analysis axis described $40.398 \%$ of total variability of piriform aperture. The greatest gender variability was present in the position of the landmark rhinion. Discriminant functional analysis of the shape and size of the piriform aperture allowed the gender determination with $64.03 \%$ accuracy for male and $70.83 \%$ accuracy for female gender. The size of the piriform aperture showed a statistically significant difference between genders. Discriminant functional analysis of the shape of the piriform aperture without affecting size enabled gender determination with 59.71\% accuracy for male and $62.5 \%$ accuracy for female.

Conclusions: Analysis showed statistically significant differences in the shape and size of piriform aperture between genders. The accuracy for gender determination based on piriform aperture was higher in females. (Folia Morphol 2022; 81, 3: 707-714)

Key words: sex determination, human skull, nasal region, geometric morphometry 


\section{INTRODUCTION}

Differences between male and female human skull are expressed in size and shape. One of the parts where sexual dimorphism is expressed is the piriform aperture which is anterior opening of the nasal cavity [27].

Classical methods and geometric morphometrics method are used to examine sexual dimorphism in the human skull [17].

Even geometric morphometric analysis of the shape and size of skeletal remains for gender determination is a relatively young; it is very interesting method for determination of the gender. The idea of digitising skeletal remains, producing three-dimensional (3D) models of them, dates back to 1980 where large number of authors around the world used this methodology [17].

Bigoni et al. [6] studied geometric morphometry in the study of the sexual dimorphism of human skulls and found the largest differences between skulls of different genders in the upper part of the face and in the form of the midsagittal line.

Franklin et al. [11] conducted several studies of sexual dimorphism on skulls from the South African region using geometric morphometry. Thus, in 2006, they conducted a study on Bantu Negroid South African populations using special software to analyse the morphological characteristics of skulls of different genders. The authors concluded that maximal lateral projection of zygomatic arches (bizigomatic width) is the best diameter for gender determination with $87 \%$ accuracy [11]. In 2007, they used geometric morphometrics method for morphological differences on 298 skulls of Bantu-speaking individuals and Khoisan and concluded that Khoizan group skulls had a pentagonal vault, a more round forehead, a small face and less prognathion than the skulls of individuals from the Bantu speaking area. On the other side, the skulls of individuals from different Bantu-speaking populations had similarities (they are brachycephalic and the mandible prognathion is less pronounced) [12]. In the same year, the sexual dimorphism of subadult mandibles was investigated by geometric morphometry. The results of this study showed that there was no gender difference in the size and shape of the subadult mandibles [14]. In 2008, using geometric morphometry, they investigated sexual dimorphism on mandibles of 225 skulls of known gender and age from five local populations of South Africa [13].
Table 1. Anthropometric points (landmarks) of piriform aperture

\begin{tabular}{lc}
\hline Anthropometric points & Position \\
\hline Apertion & Most lateral point on the piriform aperture \\
Akanthion & Point on the anterior nasal spine \\
Rhinion & Point on the top of piriform aperture \\
\hline
\end{tabular}

Kimmerle et al. [20] used geometric morphometry in their study of sexual dimorphism of the skulls and concluded that skull appearance was impacted by gender, regardless of race, while skulls of different size but of the same gender are not different in morphological characteristics.

Gonzalez et al. [16] studied sexual dimorphism on 125 images of skulls recorded with an Olympus SP-350 digital camera, which monitored 12 anthropometric points and 25 semilandmarks located in the glabella, mastoid, frontal, and zygomatic regions. They concluded that male skulls are larger and more robust than female skulls.

Chovalopoulou et al. [8] conducted several studies of the sexual dimorphism of the human skull using geometric morphometry, and in 2013 they investigated sexual dimorphism in the palate and at the base of the skull, in 2016 they analysed the sexual dimorphism of the craniofacial form [7]. In the same year, the same group of authors analysed the sexual dimorphism of the cranial vault and the mediosagittal line of the skull using geometric morphometrics method [9].

\section{MATERIALS AND METHODS}

The study included 211 human macerated and degreased skulls from Bosnian population, known gender (139 male skulls and 72 female skulls) and known age belonging to the Osteological Collection, Medical Faculty of Sarajevo.

All skulls of the tested simple were scanned using an HP 3D Structured Light Scanner Pro S2 after calibrating the scanner according to the manuscript for authors to obtain 3D skull models to perform geometric morphometric analysis of cranial sexual dimorphism. On the obtained 3D models of the tested skulls in the special programme Landmark Editor, we marked the clearly defined anthropometric points named also landmarks on the piriform aperture of each tested skull. For each examined skull, we marked four landmarks on the piriform aperture, two non-paired and one paired, whose names and their position on the skull are given in Table 1. 
From the above programme we exported data for each individual skull in the form of NTSYS format, which had information about position of landmarks in the coordinate system, which were used for analyse the shape of the piriform aperture in a programme specially created for that called MorphoJ.

\section{Statistical analysis}

The analysis of the shape of the piriform aperture was performed in the MorphoJ programme (Klingenberg 2011) in which we conducted a series of statistical analyses that give us the results of our study. The overall variability in the shape of the piriform aperture over the entire sample was examined by principal component analysis (PCA). Using Prokrust's analysis, the variation that may arise from differences in piriform aperture size, orientation, or positioning during digitisation was eliminated, leaving only information related to differences in shape. To determine the differences in the form of piriform aperture between the genders, Mahalanobis and Prokrust distances were calculated and compared by permutation tests with 1000 permutations. PCA analyses the differences in mean of form of piriform aperture between the genders.

The next step was data processing using univariate analysis (ANOVA) and multivariate analysis MANOVA. A discriminant analysis was also performed to compare the differences between male and female skulls and a validation test in MorphoJ comparing the piriform aperture forms of the two groups. In this way, even minimal gender differences can be visualised and observed. The STATISTICA for Windows 8 and MorphoJ (Klingenberg, 2011) were used in this study. The results of the study are presented using figures and tables.

\section{RESULTS}

Gender differences in the size and shape of the piriform aperture of the skull is shown by the principal components PC1 and PC2 where the largest variability was showed by the first component PC1 with $40.398 \%$ of variability, while the second component PC2 showed $36.871 \%$ of variability (Table 2 ) and patterns of charge in the shape of the piriform aperture described by the PC1 component is shown on Figure 1. Figure 2 shows the differentiation of the piriform aperture between genders by the first and second PC axes.

When we determine a statistically significant gender difference in the shape and size of the piriform
Table 2. Eigenvalues and percentage variability of shape and size of piriform aperture

\begin{tabular}{cccc}
\hline PC & Eigenvalues & $\begin{array}{c}\text { Percentage of } \\
\text { variability }\end{array}$ & $\begin{array}{c}\text { Cumulative percentage } \\
\text { of variability }\end{array}$ \\
\hline 1 & 0.00325091 & $40.398 \%$ & $40.398 \%$ \\
2 & 0.00296712 & $36.871 \%$ & $77.269 \%$ \\
3 & 0.00182927 & $22.731 \%$ & $100.000 \%$ \\
\hline
\end{tabular}

$\mathrm{PC}$ - principal component

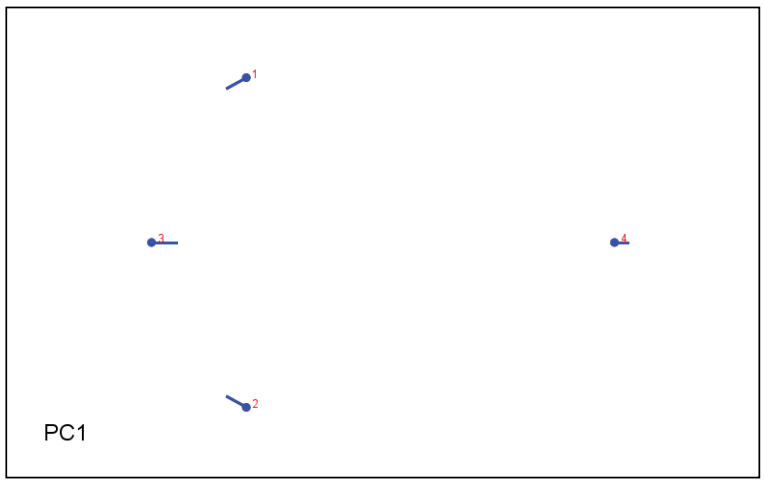

Figure 1. Patterns of change in the shape of the piriform aperture described by the PC1 component (the blue circles represent the mean values of the specific points and the lines the direction and intensity of their changes).

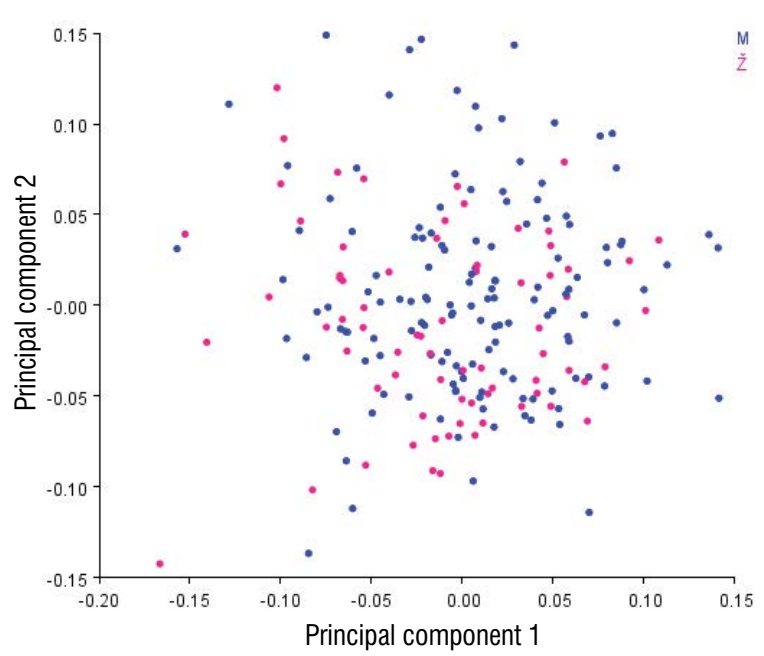

Figure 2. Position of the skulls of the test specimen based on differences in shape and size of the piriform aperture in the morphological space; $\mathrm{M}$ - men; $\mathrm{Z}$ - women.

aperture, we performed a test of correct classification, discriminant functional analysis. The calculated Procrust distance was 0.037 and the $p$ value with permutation tests of 1000 repetitions was less than 0.0001 , which shows a statistically significant gen- 
der difference in the shape and size of the piriform aperture.

Of the 139 male skulls, 89 were classified correctly as male skulls by the classification test, while 50 were classified as female skulls, representing $64.03 \%$ accuracy (Table 3).

A test of correct classification of a total of $72 \mathrm{fe}-$ male skulls 51 were classified as female skulls, while 21 female skulls were classified as male skulls and predictability for female gender was $70.83 \%$ accuracy (Table 3).

The results of discriminant functional analysis of the influence of the shape and size of the piriform aperture on the sexual dimorphism of the skulls of the examined sample are shown in Figure 3.

After the test of correct classification, a regression analysis was performed in the MorphoJ programme, where we examined the influence of the size of piriform aperture on its shape. Mean values of the size of this region are presented as centroid size where the effect of size was $3.3712 \%$ which showed statistically significant effect $(p<0.0001$, with 10,000 repetitions).

The influence of the size of the piriform aperture and the separation of the skulls in the morphological space conditioned by the size of the piriform aperture is shown on Figure 4.

After excluding the effect of size on the shape of the piriform aperture, we calculated the principal components again where the first two principal components describe $26.528 \%$ of the total variability in the shape of the piriform aperture (Table 4).

A gender difference analysis of the shape of piriform aperture was performed without affecting the size of this region, using a test of correct classification. The difference between the mean values expressed as Prokrust distance was 0.027 . The $p$ value with permutation test with 1000 repetitions was less than 0.004 , showing a statistically significant sex difference in the shape of the piriform aperture without affecting its size on the shape (Fig. 5).

The test of correct classification was out of 139 male skulls, 83 correctly classified as male skulls, which was $59.71 \%$ accuracy (Table 5 ).

The test of correct classification of 72 female skulls classified 45 skulls as female skulls, which was $62.5 \%$ accuracy (Table 5).

The results of discriminant functional analysis of the influence of the shape of the piriform aperture on
Table 3. Gender predictability based on shape and size of piriform aperture

\begin{tabular}{lcccc}
\hline & \multicolumn{2}{c}{ Predictability of the gender } & Total \\
\cline { 3 - 4 } & $\begin{array}{c}\text { Shape } \\
\text { and size }\end{array}$ & $\begin{array}{c}\text { Shape } \\
\text { and size }\end{array}$ & \\
\hline Gender & Male & 89 & 50 & 139 \\
& Female & 21 & 51 & 72 \\
Total & & 110 & 101 & 211 \\
\hline
\end{tabular}

The colours to indiate the difference between male and female sex, which is accurately determited.

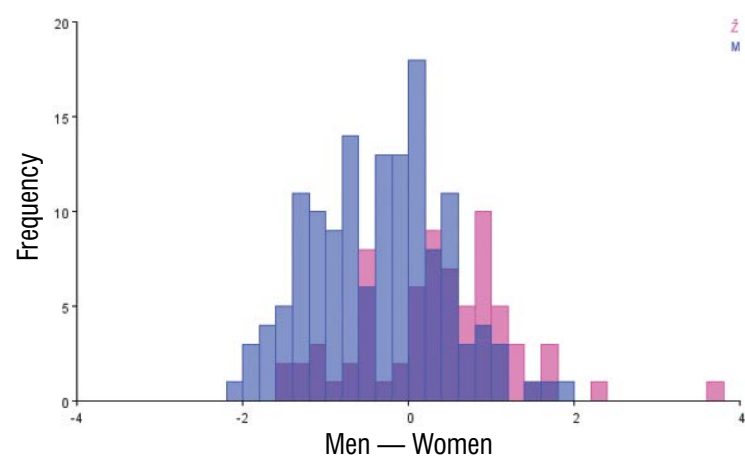

Figure 3. Discriminant functional analysis of gender differences of form of piriform aperture; $\mathrm{M}$ - men; $\mathrm{Z}$ - women.

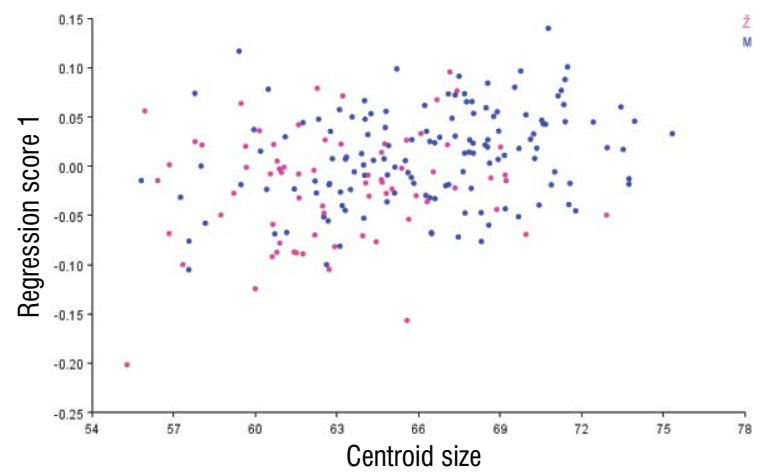

Figure 4. Influence of the size of piriform aperture on gender differences of the shape of piriform aperture; $\mathrm{M}-$ men; $\mathrm{Z}$ - women.

Table 4. Eigenvalues and percentage variability of the form of piriform aperture

\begin{tabular}{cccc}
\hline PC & Eigenvalues & $\begin{array}{c}\text { Percentage of } \\
\text { variability }\end{array}$ & $\begin{array}{c}\text { Cumulative percentage } \\
\text { of variability }\end{array}$ \\
\hline 1 & 0.00308146 & $39.628 \%$ & $39.628 \%$ \\
2 & 0.00296485 & $38.128 \%$ & $77.756 \%$ \\
3 & 0.00172970 & $22.244 \%$ & $100.000 \%$ \\
\hline
\end{tabular}

$\mathrm{PC}$ - principal component 


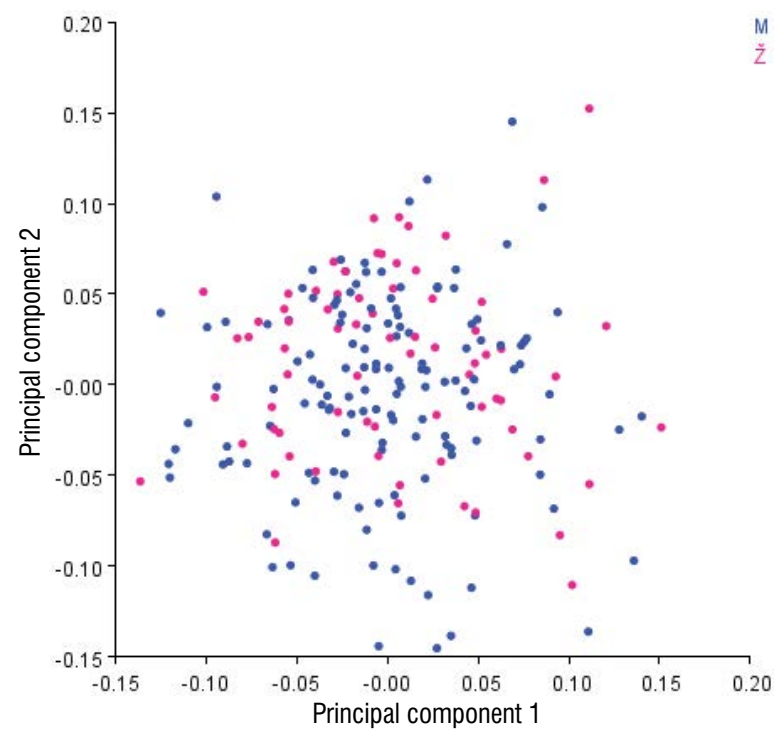

Figure 5. Position of the skulls based on differences in the shape of piriform aperture in the morphological space; $\mathrm{M}-$ men; $\mathrm{Z}$ - women.

Table 5. Predictability of gender based on the shape of piriform aperture

\begin{tabular}{lcccc}
\hline & & \multicolumn{2}{c}{ Predictability of gender } & \multirow{2}{*}{ Total } \\
\cline { 3 - 4 } & & Shape & Shape & \\
\hline \multirow{2}{*}{ Gender } & Male & 83 & 56 & 139 \\
& Female & 27 & 45 & 72 \\
Total & & 110 & 101 & 211 \\
\hline
\end{tabular}

The colours to indiate the difference between male and female sex, which is accurately determited.

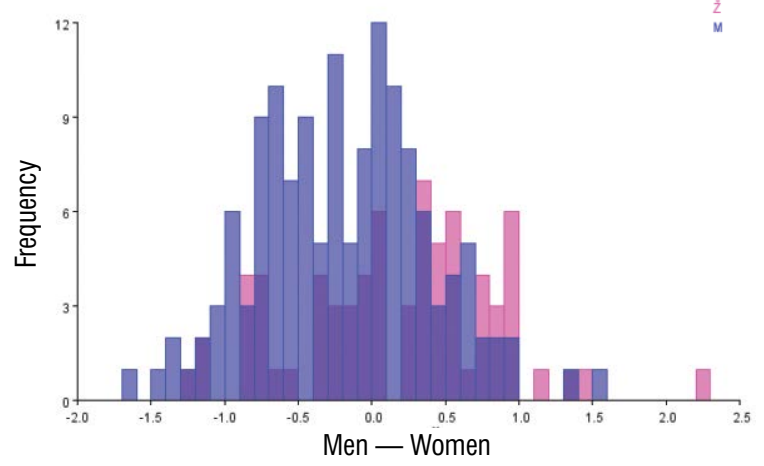

Figure 6. Discriminant functional of gender differences of shape of piriform aperture; $\mathrm{M}$ - men; $\mathrm{Z}$ - women.

the sexual dimorphism of the skulls of the examined sample are shown on Figure 6, while the interval of changes of the shape of the piriform aperture is shown on Figure 7.

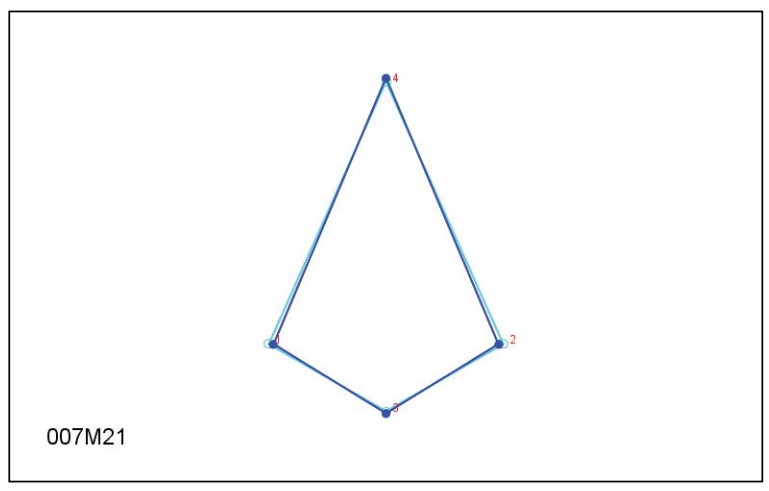

Figure 7. Interval of changes of shape of piriform aperture on examined skulls.

\section{DISCUSSION}

Gender differences of piriform aperture on 3D models of 211 human skulls (139 male skulls and 72 female skulls) was analysed using a geometric morphometric method. After the analyses, differences in the form of piriform aperture (size and shape) were observed where the first two components showed a total of $77.269 \%$ of the variability between the genders. By analysing the position of landmarks and its variability, the largest differences were observed in the position of landmark rhinion indicating the presence of differences in the height of the piriform aperture, and in the position of the right and left aperthion, indicating differences in the width of the piriform aperture.

We analysed results of other authors who studied gender differences of piriform aperture and nasal region and we noticed differences in the results that can be conditioned with different population.

In a study involving 118 human skulls (56 female skulls and 62 male skulls), nine landmarks were used for geometric morphometric analysis of the sexual dimorphism of nasal region. The results of the study showed significant differences between male and female skulls. In male skulls, the piriform aperture is higher and narrower, with a deep nasal base (position of landmark nasion and maxillonasofrontale). The piriform aperture in women is wider, the nasal bones are flattened, while the rhinion set lower, and the angle between the three landmarks, the aperthion-nasion-aperthion is sharper in the male skulls [6].

Chovalopoulou et al. [7] used geometric morphometry and eight landmarks to analyse the nasal region in her study. The results of the study did not show statistically significant significance for the sexual dimorphism of the nasal region in this study. 
Araujo et al. [4], in their research conducted in 2018, used a classical morphometric method to analyse the sexual dimorphism of piriform aperture. The results of the study showed that the height of piriform aperture was higher in the skulls of the male gender than in the skulls of the female gender, but without statistically significant sex determination, while the width of the piriform aperture had the same mean values for both genders [4].

Megia et al. [23] analysed the sexual dimorphism of the nasal cavity using geometric morphometry, which concluded that the upper nasal meatus is larger in men than in women, and that there is a difference in size and shape of choanae between male and female.

Gardner [15] conducted a study analysing differences in the shape and size of piriform aperture between the skulls of Caucasians and the black population. Discriminant functional analysis showed the possibility of population differentiation with $77.4 \%$ accuracy based on piriform aperture. The step by step method extracted three linear diameters that have statistically significant effects on population proliferation with $79 \%$ accuracy [15].

Abdelaleem et al. [1] investigated the study of sexual dimorphism of piriform aperture on 250 patients of known gender. The authors measured the height and width of the piriform aperture and discriminant analysis of the obtained data showed that both diameters had a statistically significant effect in gender determination, where the width of the piriform aperture showing greater accuracy in determination [1].

Alves et al. [2] investigated the sexual dimorphism of the palate and piriform aperture on skulls from Brazilian population. Gender determination based on piriform aperture was possible with $61.9 \%$ accuracy in this study, while height of piriform aperture was best parameter for gender determination [2].

Asghar et al. [5], in their study of 40 unknown gender skulls from the Indian population, used the results of other studies to designate 12 skulls of male gender and 28 female skulls on the basis of morphological characteristics of the examined skull, after which they analysed the sexual dimorphism of piriform aperture. They measured the height and width of piriform aperture, where the mean values for the female skulls differed significantly from the mean values of the tested diameters in the male skulls [5].

Ammani et al. [3] conducted a study on 130 computed tomography (CT) images of individuals of known gender and age from Nigeria, analysing differ- ences in the width of the nasal cavity. The results of the study showed that the lowest width of the piriform aperture was in the female group A (up to 10 years), while the largest width was in the group C (21-30 years). For men, the smallest width is in group $B$ (11-20 years), while the largest width was in group $F$ (51-60 years) [3].

Durga Devi et al. [10] investigated the sexual dimorphism of piriform aperture and nasal bones on 51 skulls of known gender from the Indian population. The results of the study showed that the height of the piriform aperture has a statistically significant effect in determination of gender, and that the shape of piriform aperture was between the oval and triangular in both genders [10].

Lopez et al. [22] analysed the gender differences of piriform aperture using classical morphometry. The study included 90 skulls of known gender, age and race from Brazil. They measured the height and upper and lower width of piriform aperture. They concluded that all measures were higher in male skulls, and that for sexual proliferation, only the height of piriform aperture showed a statistically significant effect [22].

Moreddu et al. [25] in his study analysed the gender differences of piriform aperture by classical and geometric morphometry on $170 \mathrm{CT}$ images of patients of known gender and known age using size and shape of piriform aperture. They concluded that there are statistically significant differences between men and women, in shape and size of piriform aperture, using both methods [25].

Jaiyeoba-Ojigho et al. [18] analysed piriform aperture on 51 skulls of unknown gender and age from Nigeria where they analysed the type of piriform aperture. They concluded that shape of piriform aperture on skulls in this study is typical for African population [18].

In his study on 97 radiographs of individuals from the Brazilian population, Prado et al. [26] analysed the piriform aperture using classical morphometry, concluding that all measurements (height and width of piriform aperture) were higher on the men than on the women.

Meyvaci Sertel et al. [24] analysed the piriform aperture on CT scans of 83 patients of known gender and known age ( 42 women and 41 men), concluding that all parameters of piriform aperture (height and width) had a statistically significant effect in gender determination. 
Kabakci et al. [19] published the results of a study where they analysed the piriform aperture on CT images of 200 healthy individuals from the Turkish population who did not have deformities in this area, measuring the height and width of the aperture and determining the golden ratio. The subjects were divided into groups by age. They concluded that the width of the piriform aperture increases with age [19].

In 2020, Lee et al. [21] published the results of his research in which he analyses a nasal profile on CT images of 389 Koreans of known gender and known age. In each obtained three-dimensional model, they indicated 16 specific landmarks, between which they measured 18 diameters and, based on regression analysis, created models for predicting gender.

Schlager and Rudell [28] conducted a study investigating population differences of piriform aperture on CT images of Germans ( 140 women and 127 men) and Chinese (135 women and 132 men) using 370 bilateral coordinates. They concluded that population differences are marked, and that gender differences within one population exist, and that they are similar to the gender differences observed within another population [28].

\section{CONCLUSIONS}

Principal component analysis showed that the first three PCA described $100 \%$ of variability between male and female. The first PCA axis describes $40.398 \%$ of the total variability of the analysed sample; the second PCA axis describes $36.871 \%$, while the third PCA axis describes $22.731 \%$ variability between sexes.

The greatest variability between genders was present in the position of the anthropometric point (landmark) 8 (rhinion), which is located at the top of the piriform aperture. Variability was present in the position of the first and second anthropometric points, which are the most lateral points on the piriform aperture (aperthion — right and left).

Discriminant functional analysis of the shape and size of the piriform aperture allowed the gender determination with $64.03 \%$ accuracy for male gender and $70.83 \%$ accuracy for female gender.

The size of the piriform aperture showed a statistically significant effect for gender determination ( $p<0.0001$, the percentage influence of size was $3.3712 \%)$.

Discriminant functional analysis of piriform aperture shape without affecting size enabled gender determination with $59.71 \%$ accuracy for the male and $62.5 \%$ accuracy for the female gender.

Conflict of interest: None declared

\section{REFERENCES}

1. Abdelaleem S, Younis $R$, Kader M. Sex determination from the piriform aperture using multi slice computed tomography: Discriminant function analysis of Egyptian population in Minia Governorate. Egypt J Forensic Sci. 2016; 6(4): 429-434, doi: 10.1016/j.ejfs.2016.11.003.

2. Alves N, Deana NF, Ceballos F, et al. Sex prediction by metric and non-metric analysis of the hard palate and the pyriform aperture. Folia Morphol. 2019; 78(1): 137-144, doi: 10.5603/FM.a2018.0109, indexed in Pubmed: 30484270 .

3. Ammani T, Zagga AD, Yunusa GH, et al. Cephalometric assessment of bony choanal aperture width (Bcaw) using computed tomographic (Ct) scan from usmanu danfodiyo university, Sokoto, Nigeria. IOSR-JDMS. 2019; 18(6): 36-42.

4. Araújo TM, da Silva C, de Medeiros L, et al. Morphometric analysis of piriform aperture in human skulls. Int J Morphol. 2018; 36(2): 483-487, doi: 10.4067/s071795022018000200483.

5. Asghar A, Dixit A, Rani M. Morphometric study of nasal bone and piriform aperture in human dry skull of indian origin. J Clin Diagn Res. 2016; 10(1): AC05-AC07, doi: 10.7860/ JCDR/2016/15677.7148, indexed in Pubmed: 26894050.

6. Bigoni L, Velemínská J, Brůzek J. Three-dimensional geometric morphometric analysis of cranio-facial sexual dimorphism in a Central European sample of known sex. Homo. 2010; 61(1): 16-32, doi: 10.1016/j. jchb.2009.09.004, indexed in Pubmed: 20152969.

7. Chovalopoulou ME, Valakos ED, Manolis SK. Sex determination by three-dimensional geometric morphometrics of craniofacial form. Anthropol Anz. 2016; 73(3): 195-206, doi: 10.1127/anthranz/2016/0470, indexed in Pubmed: 27490899.

8. Chovalopoulou ME, Valakos ED, Manolis SK. Sex determination by three-dimensional geometric morphometrics of the palate and cranial base. Anthropol Anz. 2013; 70(4): 407-425, doi: 10.1127/0003-5548/2013/0363, indexed in Pubmed: 24620567.

9. Chovalopoulou ME, Valakos ED, Manolis SK. Sex determination by three-dimensional geometric morphometrics of the vault and midsagittal curve of the neurocranium in a modern Greek population sample. Homo. 2016; 67(3): 173-187, doi: 10.1016/j.jchb.2015.09.007, indexed in Pubmed: 27109917.

10. Durga Devi G, Archana R, Johnson WMS, et al. Morphometric study of nasal bone and piriform aperture in human dry skull of South Indian origin. Int J Anat Res. 2018; 6(4.3): 5970-5973, doi: 10.16965/ijar.2018.386.

11. Franklin D, Freedman L, Milne N, et al. A geometric morphometric study of sexual dimorphism in the crania of indigenous southern Africans. S Afr J Sci. 2006; 102: 229-238.

12. Franklin D, Freedman L, Milne N, et al. Geometric morphometric study of population variation in indigenous south- 
ern African crania. Am J Hum Biol. 2007; 19(1): 20-33, doi: 10.1002/ajhb.20569, indexed in Pubmed: 17160981.

13. Franklin $D, O^{\prime}$ Higgins $P$, Oxnard CE. Sexual dimorphism in the mandible of indigenous South Africans: A geometric morphometric approach. S Afr J Sci. 2008; 104: 101-106.

14. Franklin D, Oxnard CE, O'Higgins $P$, et al. Sexual dimorphism in the subadult mandible: quantification using geometric morphometrics. J Forensic Sci. 2007; 52(1): 6-10, doi: 10.1111/j.1556-4029.2006.00311.x, indexed in Pubmed: 17209902.

15. Gardner S. A quantitative assessment of the morphology of the piriform aperture as an indicator of race. Forensic Med Anat Res. 2015; 03(01): 7-15, doi: 10.4236/ fmar.2015.31002.

16. Gonzalez PN, Bernal V, Perez SI. Analysis of sexual dimorphism of craniofacial traits using geometric morphometric techniques. Int J Osteoarchaeol. 2011; 21(1): 82-91, doi: 10.1002/oa.1109.

17. Ivanović $A$, Kalezić M. Evoluciona morfologija: teorijske postavke i geometrijska morfometrija. Alta Nova Zemun. 2013.

18. Jaiyeoba-Ojigho EJ, Edilamode El, Didia BC, et al. Morphometry of the nasal bones and piriform apertures of adult Nigerian skulls. Int J of Forensic Med Invest. 2019; 4(2): 22-28.

19. Kabakci A, Polat $S$, Öksüzler $M$, et al. The determination of the piriform aperture morphometry and golden ratio in healthy turkish subjects. A CT study. Int J Morphol. 2020; 38(2): 444-447, doi: 10.4067/s071795022020000200444

20. Kimmerle EH, Ross A, Slice D. Sexual dimorphism in America: geometric morphometric analysis of the craniofacial region. J Forensic Sci. 2008; 53(1): 54-57, doi: 10.1111/j.15564029.2007.00627.x, indexed in Pubmed: 18279240.
21. Lee UY, Kim H, Song JK, et al. Assessment of nasal profiles for forensic facial approximation in a modern Korean population of known age and sex. Leg Med. 2020; 42: 101646, doi: 10.1016/j.legalmed.2019.101646, indexed in Pubmed: 31751793.

22. López MC, Galdames IS, Matamala DZ, et al. Sexual dimorphism determination by piriform aperture morphometric analysis in brazilian human skulls. Int J Morphol. 2009; 27(2), doi: 10.4067/s0717-95022009000200007.

23. Megia I, Torres-Tamayo N, Martinez DG et al. 3D analysis of sexual dimorphism in the nasal cavity of modern humans. Conference paper 2018.

24. Meyvaci Sertel S, Kosif R, Bamaç B, et al. Evaluation of apertura piriformis and related cranial anatomical structures through computed tomography: golden ratio. Folia Morphol. 2019; 78(4): 839-846, doi: 10.5603/fm.a2019.0021, indexed in Pubmed: 30835344.

25. Moreddu E, Puymerail L, Michel J, et al. Morphometric measurements and sexual dimorphism of the piriform aperture in adults. Surg Radiol Anat. 2013; 35(10): 917-924, doi: 10.1007/s00276-013-1116-2, indexed in Pubmed: 23625070.

26. Prado F, Caldas R, Rossi A, et al. Piriform aperture morphometry and nasal bones morphology in Brazilian population by postero-anterior caldwell radiographys. Int J Morphol. 2011; 29(2): 393-398, doi: 10.4067/s071795022011000200014.

27. Sarač-Hadžihalilović A. Anatomically-anthropological significance of the skull. . Medical Faculty, University of Sarajevo. 2017; 66, 69-71, 74, 76.

28. Schlager S, Rüdell A. Analysis of the human osseous nasal shape--population differences and sexual dimorphism. Am J Phys Anthropol. 2015; 157(4): 571-581, doi: 10.1002/ ajpa.22749, indexed in Pubmed: 25845882. 